\title{
Real Time Lung Imaging for the Detection of Lung Injury and Alveolar Fluid Movement During Mechanical Ventilation
}

\author{
Nicolas de Prost ${ }^{*}, 1$, Jean-Damien Ricard ${ }^{2,3,4}$, Georges Saumon ${ }^{2}$ and Didier Dreyfuss ${ }^{2,3,4}$ \\ ${ }^{I}$ Department of Anesthesia and Critical Care, Massachusetts General Hospital and Harvard Medical School, Boston, \\ $M A, U S A$ \\ ${ }^{2}$ Université Paris 7 Denis Diderot, Site Xavier Bichat, 75018 Paris, France \\ ${ }^{3}$ Assistance Publique - Hôpitaux de Paris, Hôpital Louis Mourier, Service de Réanimation Médicale, F-92700, \\ Colombes, France \\ ${ }^{4}$ INSERM U722, F-75018 Paris, France
}

\begin{abstract}
Experimental ventilator-induced lung injury (VILI) is characterized by alterations in alveolar epithelial and microvascular permeability that favors the systemic dissemination of lung borne cytokines or bacteria. Animal models of VILI have been shown relevant to patient care and outcome and help explaining why most patients with the acute respiratory distress syndrome do not die from respiratory failure but from multiple organ dysfunction. Recent experimental studies also showed that adverse ventilator patterns may propel airway secretions and bacteria to previously healthy lung regions. Noninvasive imaging techniques were used for years to study the net rate of protein flow across the pulmonary microvascular endothelium and the alveolar epithelium in vivo, during normal breathing and lung inflation. More recently, the two-way protein fluxes across the alveolo-capillary barrier and the intra-pulmonary dispersion of alveolar edema have been monitored during mechanical ventilation. These experiments have provided new insights on the mechanisms of experimental VILI that may be of clinical value. This review will describe the evolution of these techniques and their main physiological and pharmacological applications in the era of VILI.
\end{abstract}

Keywords: Radionuclide imaging, respiration, artificial, blood-air barrier, acute lung injury.

\section{INTRODUCTION}

Gas is separated in the alveolar spaces from blood by a thin membrane composed of epithelial (type 1 alveolar cells) and endothelial cell layers that are either closely juxtaposed or separated by a small interstitial space. The alveolocapillary barrier is thin enough to allow efficient gas exchange and strong enough to prevent the burst of plasma proteins and water into alveoli. This barrier may however experience physical, chemical or biological insults that lead to an increased permeability to proteins [1-5]. Because the permeability of the alveolo-capillary membrane to water is much greater than that to proteins, the measurement of extravascular lung water is rather insensitive for detecting pulmonary edema of the permeability type. Imaging techniques providing a gross estimation of the epithelial and the endothelial layer permeability to proteins have been developed for more than 40 years and have had, physiological, pharmacological and clinical applications [6]. Depending of its route of administration, via the airways [79] or intravenously [10-12], a radiolabeled protein can be used for estimating epithelial or microvascular permeability, respectively.

*Address correspondence to this author at the Department of Anesthesia and Critical Care, Massachusetts General Hospital, 55 Fruit St., Boston, MA 02114, USA; Tel: (617) 726-8980; Fax: (617) 726-5985;

E-mail: nicoladeprost@gmail.com
Ventilation at high peak airway pressures produces a lung edema of the permeability type if enough protracted [13], because lung inflation, and thus tissue stretch, increases alveolar epithelial $[7,9]$ and microvascular permeability $[7$, $9,14]$. Continuously and noninvasively monitoring the changes in lung alveolar and microvascular permeability during mechanical ventilation with scintigraphic methods helped to better understand the pathophysiology of the lung injury consecutive to lung tissue overstretch, which is called ventilator-induced lung injury (VILI). In this review we will describe these imaging techniques and their use during physiological and pharmacological studies in the setting of VILI.

\section{VENTILATOR-INDUCED LUNG INJURY}

The deleterious effects of mechanical ventilation on lungs have been for long referred to as barotrauma. For many years, clinicians defined barotrauma as the occurrence of air leaks resulting in the accumulation of extra-alveolar air responsible for a number of manifestations, of which the most threatening is tension pneumothorax [15]. In addition to these "macroscopic" events, whose adverse consequences are usually immediately obvious, mechanical ventilation may produce more subtle physiological and morphological alterations, especially when high airway pressures, and thus high tidal volumes $\left(\mathrm{V}_{\mathrm{T}}\right)$, are used. Unlike the classic forms of barotrauma, our knowledge of these alterations has come only from experimental studies. Alterations in lung fluid balance, increases in endothelial and epithelial permeability, 
and severe tissue damage have been seen following mechanical ventilation in animals [16]. The clinical relevance of VILI was highlighted by the Acute Respiratory Distress Syndrome (ARDS) Network trial [17] that showed $22 \%$ reduction of mortality in patients with ARDS when the mechanical stress applied to the lungs was lessened by a reduction in $\mathrm{V}_{\mathrm{T}}$. On a mechanical point of view, four specific VILI mechanisms have been identified: a) regional overdistension caused by the application of a local stress or pressure that forces cells and tissues to assume shapes and dimensions that they do not assume during unassisted breathing [13, 14, 18]; b) so-called "low volume injury" associated with the repeated recruitment and derecruitment (airway collapse and reopening, liquid movement in distal airways) of lung units, which causes the abrasion of the epithelial airspace lining by interfacial forces $[19,20]$; c) the inactivation of surfactant triggered by large alveolar surface area oscillations [21, 22]; d) interdependence mechanisms that raise cell and tissue stress between neighboring structures with differing mechanical properties [23].

Lung inflation resulting in too high tissue stretch also promotes the systemic dissemination of lung borne cytokines $[24,25]$ or bacteria [26-28]. Although these observations may offer an explanation for the observation that most ARDS patients do not die from respiratory failure but from multiple organ dysfunction syndrome [29], similar experiments yielded conflicting findings [30, 31], thus questioning the exact relationship between VILI and multiple organ dysfunction syndrome [32]. The two-hit hypothesis has been put forward to reconcile these discrepant findings. Injurious mechanical ventilation may not be sufficient per se to promote intense lung proinflammatory cytokine secretion, but will do so in combination with another aggression (such as hemorrhagic shock or ischemiareperfusion) $[33,34]$. It was further speculated that risk and magnitude of bacterial dissemination depended on the occurrence of concomitant VILI [26-28]. Nahum et al. [27] found more positive blood cultures when dogs intratracheally instilled with Escherichia coli were ventilated with a large $\mathrm{V}_{\mathrm{T}}$ and a low positive end-expiratory pressure (PEEP) rather than with a small $\mathrm{V}_{\mathrm{T}}$ and a higher PEEP. However, these authors initiated mechanical ventilation only minutes after bacterial instillation, thereby studying massive tracheal inoculation rather than exsudative pneumonia (thus it is very unlikely that "translocating" bacteria came from the alveolar spaces). In addition, animals ventilated with the most injurious setting became bacteremic very rapidly $(\leq 30$ min) before any evidence of lung injury $\left(\mathrm{PaO}_{2}\right.$, shunt, and hemodynamics were not different from baseline). It therefore seems difficult to attribute solely to mechanical ventilation the high rate of positive blood cultures in this group of animals. Schortgen et al. extended these findings to a model of unilateral Pseudomonas aeruginosa pneumonia in rats [28]. Ventilation with a low $\mathrm{V}_{\mathrm{T}}$ and a high PEEP lessened systemic dissemination and prevented contralateral lung dissemination for the same level of overall lung inflation (same end-inspiratory pressure). Understanding these observations requires better knowledge of how ventilation impairs alveolo-capillary barrier permeability and how it interacts with the edema liquid present in distal airspaces.

\section{IMAGING OF ALVEOLO-CAPILLARY BARRIER PERMEABILITY TO PROTEINS IN VIVO}

\section{Imaging of Alveolar Epithelial Permeability}

\section{Biophysical Basis}

This technique involves the administration, by aerosolization or instillation, of a radioactively labeled tracer in the airways. The clearance of tracer activity from the lung is then measured, usually with some external radiation detection system such as small radiation probes or larger gamma cameras. The decrease of thoracic activity over time is a function of the following variables: i) lipid solubility will determine the ability of the tracer to dissolve in and then diffuse across lipid cellular membranes. This property is shared by gases, alcohol and other lipophilic solutes which penetrate these barriers so quickly that equilibration between fluid injected into the alveoli and the blood is nearly complete during the capillary transit time ( 0.75 s) [35]. In contrast, lipophobic solutes such as the electrolytes, sugars and proteins are largely confined to extracellular pathways and require no less time than several minutes before concentrations in the air spaces start to decline. ii) The molecular weight of the tracer is inversely correlated with its rate of diffusion throughout the alveolo-capillary barrier [36]. iii) The permeability surface area product of the alveolar epithelium. As previously published [37], the relationship between the alveolar concentration of the tracer $\left(\mathrm{C} / \mathrm{C}_{0}\right)$ and the permeability $(\mathrm{P})$ surface $(\mathrm{S})$ area product over time $(\mathrm{t})$ is as follows (see appendix):

$\mathrm{C} / \mathrm{C}_{0}=\mathrm{e}^{-(\mathrm{PS} / \mathrm{V}) \mathrm{t}}$

where $\mathrm{C}_{0}$ is the initial indicator concentration, $\mathrm{C}$ the indicator concentration, and $\mathrm{V}$ the volume of fluid instilled in the airways [37]. The slope of $\mathrm{C} / \mathrm{C}_{0}$ on a logarithmic coordinate against linear time would then be the constant PS/V. Distention of the lung if alveoli open by unfolding will tend to increase $\mathrm{V}$ more than $\mathrm{S}$ [37]. One might therefore expect $\mathrm{S} / \mathrm{V}$ and the value of PS/V to decrease with lung inflation. In fact, the decline in indicator concentration is accelerated by distension in instillation experiments, suggesting an increase of $P$. This finding led to the equivalent pore approach (i.e., the stretching of interendothelial pores) used by Egan [38, 39].

\section{Practical Aspects}

Beyond the above-mentioned variables, other factors can impact on the thoracic clearance of a tracer administered in the airways: i) heterogeneous spread of the tracer in the lungs due to regional changes in ventilation and, sometimes, inability to ensure adequate delivery of the tracer to the most injured regions (and thus, often the most poorly ventilated); ii) uncertainty about the site of clearance (e.g., airway $v s$ alveolus); iii) variability of the radiochemical purity of the tracer (i.e., the proportion of the total activity of the isotope bound to its carrying protein or molecule). An ideal tracer would be tightly bound to the isotope, it would be relatively simple to obtain and prepare, and its clearance rate would be fast enough to allow accurate measurements in a reasonable length of time $[8,40]$. In addition, an increase in its clearance rate would be uniquely associated with lung injury and not lung inflation. 
Peterson et al. considered these issues and compared the clearance rates of aerosolized ${ }^{99 \mathrm{~m}} \mathrm{Tc}$-labeled diethylenetriaminepentaacetate ${ }^{99 \mathrm{~m}} \mathrm{Tc}-\mathrm{DTPA}$, mol wt $\left.492 \mathrm{Da}\right),{ }^{99 \mathrm{~m}} \mathrm{Tc}-$ labeled albumin (mol wt $69000 \mathrm{Da}$ ) and ${ }^{99 \mathrm{~m}} \mathrm{Tc}$-aggregated albumin (mol wt $383000 \mathrm{Da}$ ) from the lungs of anesthetized sheep subjected to lung inflation or lung injury induced by intravenous oleic acid [41]. Spontaneous clearance of ${ }^{99 \mathrm{~m}} \mathrm{Tc}-$ DTPA was high $(0.42 \pm 0.15 \% / \mathrm{min})$ and significantly and equivalently increased after oleic acid injection and application of a PEEP of $10 \mathrm{cmH}_{2} \mathrm{O} .{ }^{99 \mathrm{~m}} \mathrm{Tc}$-albumin exhibited a much lower spontaneous clearance $(0.06 \pm 0.02 \% / \mathrm{min})$ that was not modified by PEEP application and increased after oleic acid injection. The ${ }^{99 \mathrm{~m}} \mathrm{Tc}$-aggregated albumin clearance rate was unchanged by lung inflation and increased slightly with lung injury. The authors concluded that ${ }^{99 \mathrm{~m}} \mathrm{Tc}-$ albumin was the best indicator for studying the effects of lung epithelial injury on protein transport out of the air spaces.

\section{Imaging of Pulmonary Microvascular Permeability}

Measuring the time-dependent accumulation of an intravenously administered radioactively labeled protein tracer into lung tissue (i.e., from plasma to interstitium) has been used for years to determine whether or not the integrity of the capillary endothelial barrier was compromised $[6,42]$. However, since the tracer moves to other tissues, its plasma concentration decreases over time. Therefore, the count rate decreases at the detector, which might overwhelm the slight increase due to lung influx of the tracer. Normalization of the activity of the tracer is thus required. In 1957 Aviado and Schmidt attempted to follow the development of alloxaninduced pulmonary edema using diffusible ( ${ }^{131} \mathrm{I}$-albumin) and nondiffusible $\left({ }^{32} \mathrm{P}\right.$-labeled red blood cells) tracers [43]. Due to technological limitations, they could only use one tracer in each animal. They however observed and increase in ${ }^{131} \mathrm{I}$ counts in lungs occurring at a time when ${ }^{32} \mathrm{P}$ counts were known to decrease. They suggested that this reflected increased extravasation of plasma albumin in lung parenchyma. In 1968, Potchen and Welch successfully distinguished gamma emissions from simultaneously injected diffusible $\left({ }^{131} \mathrm{I}\right.$-albumin $)$ and nondiffusible $\left({ }^{51} \mathrm{Cr}\right.$ labeled red blood cells) tracers using a pulse height analyzer [44] thus allowing larger applications of this technique. Gorin et al. further validated the physiological relevance of this method by showing a correlation between the pulmonary ${ }^{111}$ In-transferrin transvascular flux and the tracer protein accumulation in lung lymph in sheep submitted to various types of lung injury [45]. The same authors showed the feasibility of this technique in humans, although the need to label red blood cells in vitro before restituting them to the patient remained a major constraint [46]. Roselli et al. finally simplified and homogenized this technique by validating the normalized slope index, that is, "the time rate of change of radioactivity originating from protein in lung interstitium divided by this ratio at time 0 , and corrected for blood volume changes". Only one tracer could be used providing the decrease of its plasma activity over time would be accounted for by measuring the activity of a fixed plasma volume at different time points and then normalizing the detector count rate by the plasma count rate $[47,48]$ or by selecting a vascular region with a gamma camera in order to quantify plasma protein clearance without the need for a blood sample [49-51].

Indium $\left({ }^{113 \mathrm{~m}} \mathrm{In}\right.$ or $\left.{ }^{111} \mathrm{In}\right)$ has been widely used as it strongly binds to transferrin in vivo and forms a good tracer of passive protein movement because it does not bind to transferrin receptors [52]. Basran et al. noninvasively measured its pulmonary accumulation in ARDS patients at bedside using a portable probe radiation detector. They showed clearly separated values of accumulation indexes between ARDS patients and healthy subjects [10]. They further used this method to evaluate the effect of a pharmacological intervention on pulmonary microvascular permeability. They observed that patients whose pulmonary protein accumulation indexes decreased after terbutaline challenge (i.e., responders) were more likely to survive than those who did not respond [53]. The growing enthusiasm for this technique was however reduced when Schuster et al. failed to discriminate patients with noncardiogenic and cardiogenic pulmonary edema using the normalized slope index after intravenous injection of ${ }^{99 \mathrm{~m}} \mathrm{Tc}$-albumin [54]. The authors hypothesized that the overlap observed in the permeability indexes of the two groups of patients was due to the occurrence of capillary stress failure associated with high intravascular pressures which may have allowed rapid egress of radiolabeled proteins from the vascular space [55].

\section{Simultaneous Imaging of Alveolar Epithelial and Pulmonary Microvascular Permeability to Proteins}

\section{Physiological Relevance}

Permeability to proteins of the epithelial and endothelial layers widely differs, alveolar epithelium being much less permeable than the endothelium [11]. Moreover, the response of each layer of the alveolo-capillary membrane to physical, chemical or biological insults may differ, depending on insult type [2, 4, 5]. For instance, Pseudomonas aeruginosa elastase on the alveolar side produces alveolar epithelium leakiness that manifests as an increase in the clearance of aerosolized albumin, without evidence of edema [1], whereas chronic heart failure increases protein fluxes in both directions [56]. During lung inflation, alveolar permeability to proteins has been shown to increase in sheep [41, 57] and in humans [58]. On the other hand, short periods of overinflation resulted in a reversible increase in pulmonary microvascular permeability to albumin and perhaps some increase in alveolar epithelial permeability as radiolabeled albumin injected in the systemic circulation was recovered in bronchoalveolar lavage fluid [59]. More sustained high tidal volume ventilation produced endothelial and epithelial cell alterations and a pulmonary edema of the permeability type [16]. Noninvasively monitoring the simultaneous changes of lung microvascular and alveolar permeability to proteins in vivo with a model combining an alveolar and a systemic tracer allowed us to independently examine the response of each layer of the alveolo-capillary barrier during lung inflation [60].

\section{Description of the Double-Isotope Model}

Briefly (see reference [60] for a more detailed description), male Wistar rats were anesthetized, tracheostomized and mechanically ventilated. About $400 \mu \mathrm{Ci}$ of ${ }^{111}$ In chloride were injected intravenously. A solution 
containing ${ }^{99 \mathrm{~m}} \mathrm{Tc}$-albumin $(\sim 600 \quad \mu \mathrm{Ci})$ was selectively instilled in one lung. Pulmonary microvascular permeability was estimated using the normalized lung-to-heart activity ratio of ${ }^{111}$ In-transferrin which is related to the normalized slope index [61]. This index (lung-to-heart ratio divided by its initial value) accurately reflects ${ }^{111}$ In-transferrin plasma to lung flux assuming that lung and heart blood volumes do not vary during the observation period. Alveolar epithelial permeability was estimated by measuring the decrease of ${ }^{99 \mathrm{~m}} \mathrm{Tc}$-albumin in a region of interest (ROI) drawn over the thorax and fitted with a two-exponential decay equation. Scintigraphic imaging was performed as follows: continuous planar thoracic acquisitions were performed using a small animal gamma camera. Acquisition windows were 140 $\mathrm{KeV} \pm 15 \%$ for ${ }^{99 \mathrm{~m}} \mathrm{Tc}$ and $245 \mathrm{KeV} \pm 20 \%$ for ${ }^{111} \mathrm{In}\left({ }^{99 \mathrm{~m}} \mathrm{Tc}\right.$ does not emit in this energy window). Spillover of ${ }^{111}$ In in the ${ }^{99 \mathrm{~m}} \mathrm{Tc}$ energy window $\left(\sim 60 \%{ }^{111}\right.$ In counts in the $245-\mathrm{KeV}$ window) was subtracted, and ${ }^{99 \mathrm{~m}} \mathrm{Tc}$ activity decay was taken into account. ${ }^{99 \mathrm{~m}} \mathrm{Tc} /{ }^{11}$ In lung count ratio in the ${ }^{99 \mathrm{~m}} \mathrm{Tc}$ window was always $\sim 10$ so that the correction always remained below $10 \%$ of ${ }^{99 \mathrm{~m}} \mathrm{Tc}$ counts. Acquisition lasted 120 min without interruption. A $30 \mathrm{~min}$ long quality control acquisition was performed at the beginning of each experiment while ventilating the animal with protective settings in order to make sure that the baseline diffusion of each tracer through the alveolo-capillary barrier was negligible. An intervention could be performed once this acquisition was completed.

\section{Applications of the Model}

We assessed the effect of lung inflation on alveolar epithelial and endothelial permeability to proteins by ventilating 4 groups of rats with different end-inspiratory plateau pressures (Pplat). Pplat tested were 15, 20, 25 and 30 $\mathrm{cmH}_{2} \mathrm{O}$, corresponding to $\mathrm{V}_{\mathrm{T}}$ of $7.8 \pm 0.31,13.7 \pm 4.69$, $22.2 \pm 2.12$ and $25.9 \pm 1.76 \mathrm{~mL} / \mathrm{kg}$. The main finding of this study was that the same end-inspiratory pressure threshold (between 20 and $25 \mathrm{cmH}_{2} \mathrm{O}$ ) was observed for epithelial and endothelial permeability changes (Fig. 1). Interestingly, this threshold pressure approximately corresponds to the pressure at which a decrease in the respiratory system pressure- volume curve slope (the so-called "upper inflection point") is observed in rats [62], which may reflect the occurrence of lung tissue overstretch. Whereas protein flux from plasma to alveolar space was constant over time, the rate at which ${ }^{99 \mathrm{~m}} \mathrm{Tc}$-albumin left air spaces decreased with time, as previously described [41, 63]. Application of a threecompartment model including an intermediate interstitial space whose volume could change over time explained this pattern. This simple double-isotope imaging technique allowed to noninvasively explore the simultaneous changes of lung microvascular and alveolar permeability to proteins in vivo.

This model was further used to assess the effect of pharmacological interventions in the setting of VILI. Changes in epithelial and endothelial permeability induced by injurious mechanical ventilation with or without PEEP were challenged by a $\beta_{2}$-agonist (terbutaline) administered either intratracheally or intraperitoneally [64]. High volume ventilation resulted in immediate leakage of ${ }^{99 \mathrm{~m}} \mathrm{Tc}$-albumin from alveolar spaces and increased pulmonary uptake of systemic ${ }^{111}$ In-transferrin. Terbutaline in the instilled solution and PEEP lessened alveolar ${ }^{99 \mathrm{~m}} \mathrm{Tc}$-albumin leakage and ${ }^{111}$ In-transferrin uptake due to high volume ventilation, whereas terbutaline given intra-peritoneally only lessened ${ }^{111}$ In-transferrin uptake. Terbutaline in the instilled solution also lessened the increase in lung wet-to-dry weight ratio due to high volume ventilation. Our simple double-isotope imaging model allowed us to first describe the effect of a $\beta_{2}-$ agonist on alveolar and endothelial permeability changes during high volume ventilation. The effect of PEEP was likely due to a decrease in tidal volume excursions, because it has been shown that beyond absolute stretch level, the magnitude of a cyclic stretch also affected cell response to mechanical challenge [65].

\section{NONINVASIVE ASSESSMENT OF INTRAPULMO- NARY FLUID DISPERSION DURING MECHANICAL VENTILATION}

As seen above, mechanical ventilation may favor systemic dissemination of sepsis and inflammation during

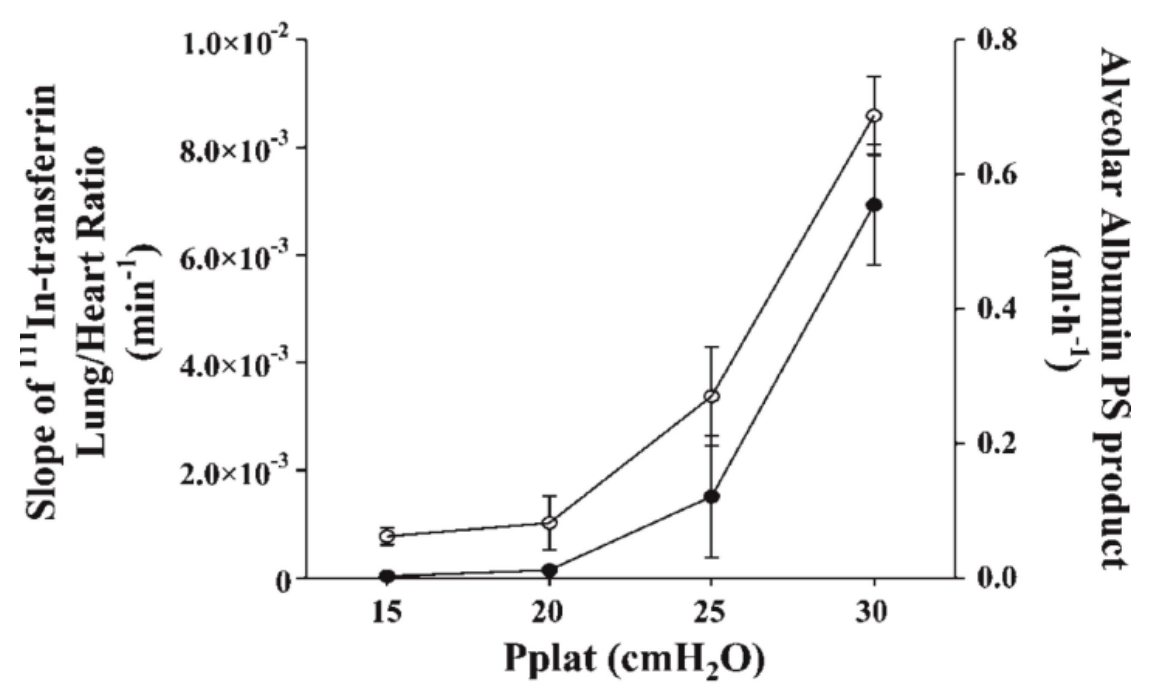

Fig. (1). Relationship between Pplat and ${ }^{111}$ In-transferrin lung-to-heart ratio slopes (left axis, open circles) and alveolar ${ }^{99 \mathrm{~m}}$ Tc-albumin permeability-surface area product (right axis, full circles); Reproduced from [60] with authorization. 

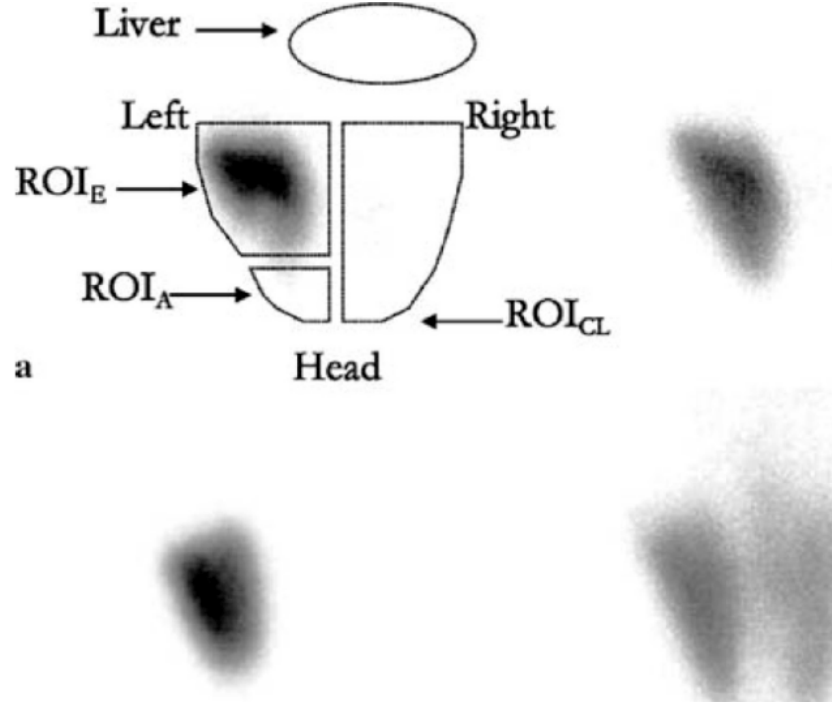

b
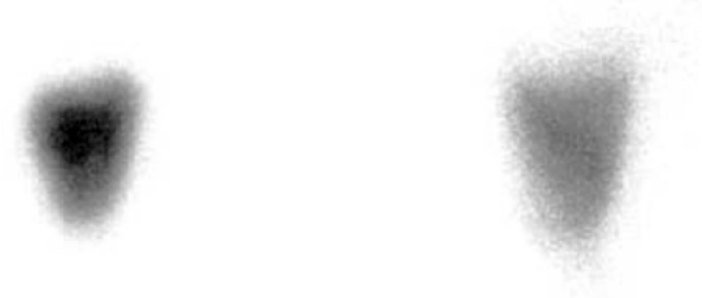

c

Fig. (2). Examples of scintigraphy images integrating the $15 \mathrm{~min}$ following instillation ( $\mathrm{t} 0-\mathrm{t} 15$; left panels) and the last $15 \mathrm{~min}$ of the experiment (t195-t210; right panels). Regions of interest (ROIs) were drawn around initial focus of edema $\left(\mathrm{ROI}_{\mathrm{E}}\right)$, the apex of the same lung $\left(\mathrm{ROI}_{\mathrm{A}}\right)$, the contralateral lung $\left(\mathrm{ROI}_{\mathrm{CL}}\right)$ and over the thorax $\left(\mathrm{ROI}_{\mathrm{T}}\right)$. At baseline (left panels), all animals were ventilated with a tidal volume of $8 \mathrm{~mL} / \mathrm{kg}$ and a PEEP of $2 \mathrm{cmH}_{2} \mathrm{O}$ and exhibited focalized localization of the tracer in the left lung. When the same ventilator settings were kept during the experiment (a), the tracer remained remarkably confined in the initial zone; there was no contra-lateral and slight homolateral dissemination. High volume ventilation (Pplat $=30 \mathrm{cmH}_{2} \mathrm{O}$ ) with no PEEP (b) induced strong homo and contralateral dispersion of the tracer and systemic leakage as attested by the evident decrease in overall activity. High volume ventilation with $6 \mathrm{cmH}_{2} \mathrm{O}$ PEEP (c) induced systemic, but not contralateral, dissemination of the tracer. Reproduced from [66] with authorization.

bacterial pneumonia. There is also growing evidence that ventilator settings may localize or disperse proteinaceous lung edema or bacteria. In an unilateral model of Pseudomonas aeruginosa pneumonia in rats, Schortgen et al. showed that high volume ventilation with no PEEP promoted contralateral bacterial seeding. Interestingly, ventilation at the same end-inspiratory pressure but with a high PEEP, and thus a lower $\mathrm{V}_{\mathrm{T}}$, prevented contralateral lung dissemination [28]. In order to better understand these observations, we studied the potential for adverse ventilator patterns to

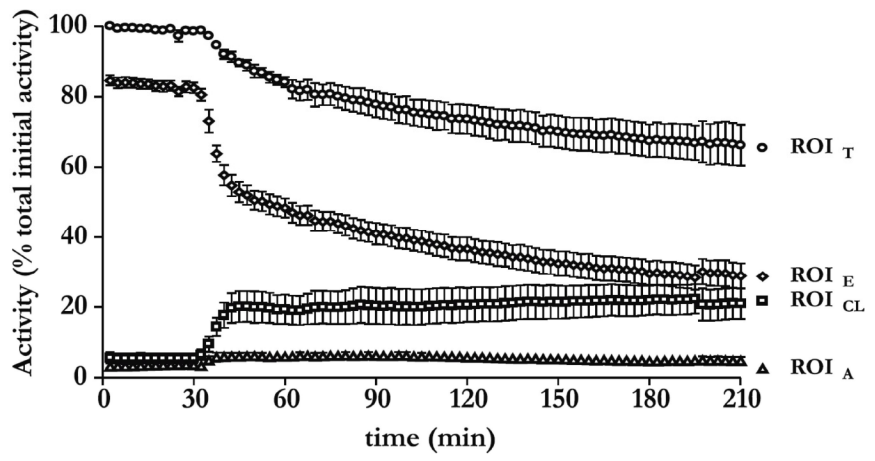

Fig. (3). Activity changes in the four $\mathrm{ROI}_{\mathrm{S}}$ (as defined in the legend of Fig. 2) expressed as percentage of initial total activity for 6 animals ventilated with a tidal volume of $8 \mathrm{~mL} / \mathrm{kg}$ and a PEEP of 2 $\mathrm{cmH}_{2} \mathrm{O}$ for the 30 first min. Notice that the activity is remarkably stable in all ROIs. When high volume ventilation with no PEEP was started (after $30 \mathrm{~min}$ ), there was an almost immediate decrease of activity in $\mathrm{ROI}_{\mathrm{E}}$ and $\mathrm{ROI}_{\mathrm{T}}$ and a dramatic increase in $\mathrm{ROI}_{\mathrm{CL}}$. Changes in $\mathrm{ROI}_{\mathrm{T}}$ activity displayed a two phase's exponential decay: activity decreased fastly between $\mathrm{t} 30$ and t60 and more slowly between t60 and t210. Reproduced from [66] with authorization.

disperse localized radiolabeled alveolar edema to the opposite lung [66]. A ${ }^{99 m}$ Tc-labeled albumin solution was instilled in a distal airway. This protocol produced a zone of alveolar flooding that stayed localized during conventional ventilation or spontaneous breathing. High end-inpiratory pressure ventilation dispersed alveolar liquid in the lungs. This dispersion was prevented by PEEP even when $\mathrm{V}_{\mathrm{T}}$ was the same and thus end-inspiratory pressure even higher (Fig. 2). Interestingly, contralateral liquid dispersion began almost immediately after high volume ventilation was started, suggesting that this dispersion might be the consequence of a convective movement induced by the ventilation (Fig. 3). High-inspiratory and -expiratory flows favored fluid transport back and forth toward the alveoli and the airways. Moreover, in the heterogeneous lung, fluid transfer may be propelled toward regions of normal lung because they have a normal compliance and thus receive high inspiratory flows. PEEP may have prevented dispersion by avoiding lung collapse and stabilizing edema fluid in the distal airways. These findings are in keeping with and help understanding the intrapulmonary dispersion of $P$. aeruginosa during a similar ventilation modality [28]. The clinical relevance of the movement of such noxious biofluids in the airways has recently been addressed [67].

\section{CONCLUSION}

Simple noninvasive imaging techniques can be used to noninvasively study the changes in lung microvascular and alveolar permeability to proteins in vivo and the movement of fluids in the lungs during mechanical ventilation. Continuously and simultaneously monitoring such variables might be of great interest in experimental research on VILI as it allows the assessment of physiological or pharmacological interventions [68, 69].

\section{APPENDIX}

Relationship between changes in the alveolar concentration of the tracer $\left(\mathrm{C} / \mathrm{C}_{0}\right)$ and the permeability surface area product of the alveolar epithelium: as previously 
published [37], the rate of solute diffusion (dQ/dt) through membranes is directly proportional to membrane surface area (S) and the concentration gradient $(\mathrm{dc} / \mathrm{dx})$ in accordance with Fick's First Law of Diffusion:

$\mathrm{dQ} / \mathrm{dt}=-\mathrm{DS} \mathrm{dc} / \mathrm{dx}$

where D represents the diffusion coefficient per unit of surface area. As the concentration difference across the membrane $\Delta \mathrm{c}$ can only be measured, this equation becomes:

$\mathrm{dQ} / \mathrm{dt}=-\mathrm{PS} \Delta \mathrm{c}$

where PS is the whole membrane permeability (P) surface (S) area product. Assuming that much of the fluid instilled into the airways will reach alveoli, the indicator concentration $(\mathrm{C})$ of the fluid will decline uniformly in the volume $(\mathrm{V})$ instilled:

$\mathrm{dQ} / \mathrm{dt}=\mathrm{VdC} / \mathrm{dt}=-\mathrm{PS} \Delta \mathrm{c}$

If plasma concentration remains low, this relationship can be simplified to:

$\mathrm{dC} / \mathrm{dt}=-\mathrm{PSC} / \mathrm{V}$

Solution of equation (4) yields the following:

$\mathrm{C} / \mathrm{C}_{0}=\mathrm{e}^{-(\mathrm{PS} / \mathrm{V}) \mathrm{t}}$

where $\mathrm{C}_{0}$ is the initial indicator concentration [37].

\section{REFERENCES}

[1] Azghani AO, Connelly JC, Peterson BT, Gray LD, Collins ML, Johnson AR. Effects of Pseudomonas aeruginosa elastase on alveolar epithelial permeability in guinea pigs. Infect Immun 1990; 58(2): 433-8.

[2] Ermert L, Rossig R, Hansen T, Schutte H, Aktories K, Seeger W. Differential role of actin in lung endothelial and epithelial barrier properties in perfused rabbit lungs. Eur Respir J 1996; 9(1): 93-9.

[3] Jefferies AL, Fung D, Mullen JB. Fibrinogen depletion and control of permeability in oleic acid lung injury. Am Rev Respir Dis 1991; 143(3): 618-24.

[4] Kawkitinarong K, Linz-McGillem L, Birukov KG, Garcia JG. Differential regulation of human lung epithelial and endothelial barrier function by thrombin. Am J Respir Cell Mol Biol 2004; 31(5): 517-27.

[5] Wiener-Kronish JP, Albertine KH, Matthay MA. Differential responses of the endothelial and epithelial barriers of the lung in sheep to Escherichia coli endotoxin. J Clin Invest 1991; 88(3): 864-75.

[6] Staub NC, Hyde RW, Crandall E. NHLBI workshop summary. Workshop on techniques to evaluate lung alveolar-microvascular injury. Am Rev Respir Dis 1990; 141(1): 1071-7.

[7] Cooper JA, van der Zee H, Line BR, Malik AB. Relationship of end-expiratory pressure, lung volume, and $99 \mathrm{mTc}-\mathrm{DTPA}$ clearance. J Appl Physiol 1987; 63(4): 1586-90.

[8] Huchon GJ, Montgomery AB, Lipavsky A, Hoeffel JM, Murray JF. Respiratory clearance of aerosolized radioactive solutes of varying molecular weight. J Nucl Med 1987; 28(5): 894-902.

[9] Marks JD, Luce JM, Lazar NM, Wu JN, Lipavsky A, Murray JF. Effect of increases in lung volume on clearance of aerosolized solute from human lungs. J Appl Physiol 1985; 59(4): 1242-8.

[10] Basran GS, Byrne AJ, Hardy JG. A noninvasive technique for monitoring lung vascular permeability in man. Nucl Med Commun 1985; 6(1): 3-10.

[11] Gorin AB, Stewart PA. Differential permeability of endothelial and epithelial barriers to albumin flux. J Appl Physiol 1979; 47(6): 1315-24.

[12] Mintun MA, Dennis DR, Welch MJ, Mathias CJ, Schuster DP. Measurements of pulmonary vascular permeability with PET and gallium-68 transferrin. J Nucl Med 1987; 28(11): 1704-16.

[13] Dreyfuss D, Basset G, Soler P, Saumon G. Intermittent positivepressure hyperventilation with high inflation pressures produces pulmonary microvascular injury in rats. Am Rev Respir Dis 1985; 132(4): 880-4.
[14] Parker JC, Townsley MI, Rippe B, Taylor AE, Thigpen J. Increased microvascular permeability in dog lungs due to high peak airway pressures. J Appl Physiol 1984; 57(6): 1809-16.

[15] Pingleton SK. Complications of acute respiratory failure. Am Rev Respir Dis 1988; 137(6): 1463-93.

[16] Dreyfuss D, Saumon G. Ventilator-induced lung injury: lessons from experimental studies. Am J Respir Crit Care Med 1998; 157(1): 294-323.

[17] ARDS-Network. Ventilation with lower tidal volumes as compared with traditional tidal volumes for acute lung injury and the acute respiratory distress syndrome. The Acute Respiratory Distress Syndrome Network. N Engl J Med 2000; 342(18): 1301-8.

[18] Vlahakis NE, Hubmayr RD. Cellular stress failure in ventilatorinjured lungs. Am J Respir Crit Care Med 2005; 171(12): 1328-42.

[19] Bilek AM, Dee KC, Gaver DP, 3rd. Mechanisms of surfacetension-induced epithelial cell damage in a model of pulmonary airway reopening. J Appl Physiol 2003; 94(2): 770-83.

[20] Muscedere JG, Mullen JB, Gan K, Slutsky AS. Tidal ventilation at low airway pressures can augment lung injury. Am J Respir Crit Care Med 1994; 149(5): 1327-34.

[21] Ito Y, Veldhuizen RA, Yao LJ, McCaig LA, Bartlett AJ, Lewis JF Ventilation strategies affect surfactant aggregate conversion in acute lung injury. Am J Respir Crit Care Med 1997; 155(2): 493-9.

[22] Savov J, Silbajoris R, Young SL. Mechanical ventilation of rat lung: effect on surfactant forms. Am J Physiol 1999; 277(1): L3206.

[23] Mead J, Takishima T, Leith D. Stress distribution in lungs: a model of pulmonary elasticity. J Appl Physiol 1970; 28(5): 596-608.

[24] Ranieri VM, Suter PM, Tortorella C, et al. Effect of mechanical ventilation on inflammatory mediators in patients with acute respiratory distress syndrome: a randomized controlled trial. JAMA 1999; 282(1): 54-61.

[25] Tremblay L, Valenza F, Ribeiro SP, Li J, Slutsky AS. Injurious ventilatory strategies increase cytokines and c-fos m-RNA expression in an isolated rat lung model. J Clin Invest 1997: 99(5): 944-52.

[26] Murphy DB, Cregg N, Tremblay L, et al. Adverse ventilatory strategy causes pulmonary-to-systemic translocation of endotoxin. Am J Respir Crit Care Med 2000; 162(1): 27-33.

[27] Nahum A, Hoyt J, Schmitz L, Moody J, Shapiro R, Marini JJ. Effect of mechanical ventilation strategy on dissemination of intratracheally instilled Escherichia coli in dogs. Crit Care Med 1997; 25(10): 1733-43.

[28] Schortgen F, Bouadma L, Joly-Guillou ML, Ricard JD, Dreyfuss $\mathrm{D}$, Saumon G. Infectious and inflammatory dissemination are affected by ventilation strategy in rats with unilateral pneumonia. Intensive Care Med 2004; 30(4): 693-701.

[29] Montgomery AB, Stager MA, Carrico CJ, Hudson LD. Causes of mortality in patients with the adult respiratory distress syndrome. Am Rev Respir Dis 1985; 132(3): 485-9.

[30] Ricard JD, Dreyfuss D, Saumon G. Production of inflammatory cytokines in ventilator-induced lung injury: a reappraisal. Am J Respir Crit Care Med 2001; 163(5): 1176-80.

[31] Verbrugge SJ, Uhlig S, Neggers SJ, et al. Different ventilation strategies affect lung function but do not increase tumor necrosis factor-alpha and prostacyclin production in lavaged rat lungs in vivo. Anesthesiology 1999; 91(6): 1834-43.

[32] Dreyfuss D, Ricard JD, Saumon G. On the physiologic and clinical relevance of lung-borne cytokines during ventilator-induced lung injury. Am J Respir Crit Care Med 2003; 167(11): 1467-71.

[33] Bouadma L, Dreyfuss D, Ricard JD, Martet G, Saumon G. Mechanical ventilation and hemorrhagic shock-resuscitation interact to increase inflammatory cytokine release in rats. Crit Care Med 2007; 35(11): 2601-6.

[34] Bouadma L, Schortgen F, Ricard JD, Martet G, Dreyfuss D, Saumon G. Ventilation strategy affects cytokine release after mesenteric ischemia-reperfusion in rats. Crit Care Med 2004; 32(7): 1563-9.

[35] Casaburi R, Wasserman K, Effros RM. Detection and measurement of pulmonary edema. In: Staub NC, Ed. Lung, Water and solute exchange. Marcel Dekker, New York, 1978; pp. 323-63.

[36] Enna SJ, Schanker LS. Absorption of drugs from the rat lung. Am J Physiol 1972; 223(5): 1227-31.

[37] Effros RM, Mason GR. Measurements of pulmonary epithelial permeability in vivo. Am Rev Respir Dis 1983; 127(2): S59-65. 
[38] Egan EA. Response of alveolar epithelial solute permeability to changes in lung inflation. J Appl Physiol 1980; 49(6): 1032-6.

[39] Egan EA. Lung inflation, lung solute permeability, and alveolar edema. J Appl Physiol 1982; 53(1): 121-5.

[40] Huchon GJ, Little JW, Murray JF. Assessment of alveolar-capillary membrane permeability of dogs by aerosolization. J Appl Physiol 1981; 51(4): 955-62.

[41] Peterson BT, Dickerson KD, James HL, Miller EJ, McLarty JW, Holiday DB. Comparison of three tracers for detecting lung epithelial injury in anesthetized sheep. J Appl Physiol 1989; 66(5): 2374-83.

[42] Schuster DP. Imaging VILI: present and future possibilities. In: Dreyfuss DSG, Hubmayr RD, Eds. Ventilator-induced lung injury. London: Taylor \& Francis 2006; pp. 447-74.

[43] Aviado DM, Jr., Schmidt CF. Pathogenesis of pulmonary edema by alloxan. Circ Res 1957; 5(2): 180-6.

[44] Potchen EJ, Welch MJ. Radioisotopic assessment of extravascular albumin an an index of lymph transport. Lymphology 1968; 1(2): 59-64.

[45] Gorin AB, Weidner WJ, Demling RH, Staub NC. Noninvasive measurement of pulmonary transvascular protein flux in sheep. $\mathrm{J}$ Appl Physiol 1978; 45(2): 225-33.

[46] Gorin AB, Kohler J, DeNardo G. Noninvasive measurement of pulmonary transvascular protein flux in normal man. J Clin Invest 1980; 66(5): 869-77.

[47] Gorin AB. Noninvasive measurement of regional interstitial lung volume in sheep. J Appl Physiol 1988: 64(4); 1561-6.

[48] Welsh CH, Dauber IM, Weil JV. Endotoxin increases pulmonary vascular protein permeability in the dog. J Appl Physiol 1986; 61(4): 1395-1402.

[49] Sugerman HJ, Hirsch JI, Strash AM, et al. Preliminary report. Gamma camera detection of oleic acid alveolar-capillary albumin leak. J Surg Res 1980; 29(1): 93-9.

[50] Sugerman HJ, Hirsch JI, Tatum JL, Strash AM, Sharp DE, Greenfield LJ. Comparative scintigraphy in oleic acid pulmonary microvascular injury. Crit Care Med 1982; 10(1): 31-3.

[51] Tatum JL, Strash AM, Sugerman HJ, Hirsch JI, Beachley MC, Greenfield LJ. Single isotope evaluation of pulmonary capillary protein leak (ARDS model) using computerized gamma scintigraphy. Invest Radiol 1981; 16(6): 473-8.

[52] Otsuki H, Brunetti A, Owens ES, Finn RD, Blasberg RG. Comparison of iron-59, indium-111, and gallium-69 transferrin as a macromolecular tracer of vascular permeability and the transferrin receptor. J Nucl Med 1989; 30(10): 1676-85.

[53] Basran GS, Hardy JG, Woo SP, Ramasubramanian R, Byrne AJ. Beta-2-adrenoceptor agonists as inhibitors of lung vascular permeability to radiolabelled transferrin in the adult respiratory distress syndrome in man. Eur J Nucl Med 1986; 12(8): 381-4.
[54] Schuster DP, Stark T, Stephenson J, Royal H. Detecting lung injury in patients with pulmonary edema. Intensive Care Med 2002; 28(9): 1246-53.

[55] West JB, Tsukimoto K, Mathieu-Costello O, Prediletto R. Stress failure in pulmonary capillaries. J Appl Physiol 1991; 70(4): 173142.

[56] De Pasquale CG, Bersten AD, Doyle IR, Aylward PE, Arnolda LF. Infarct-induced chronic heart failure increases bidirectional protein movement across the alveolocapillary barrier. Am J Physiol Heart Circ Physiol 2003; 284(6): H2136-45.

[57] Peterson BT, James HL, McLarty JW. Effects of lung volume on clearance of solutes from the air spaces of lungs. J Appl Physiol 1988; 64(3): 1068-75.

[58] Nolop KB, Maxwell DL, Royston D, Hughes JM. Effect of raised thoracic pressure and volume on $99 \mathrm{mTc}-\mathrm{DTPA}$ clearance in humans. J Appl Physiol 1986; 60(5): 1493-7.

[59] Dreyfuss D, Soler P, Saumon G. Spontaneous resolution of pulmonary edema caused by short periods of cyclic overinflation. J Appl Physiol 1992; 72(6): 2081-9.

[60] de Prost N, Dreyfuss D, Saumon G. Evaluation of two-way protein fluxes across the alveolo-capillary membrane by scintigraphy in rats: effect of lung inflation. J Appl Physiol 2007; 102(2): 794-802.

[61] Roselli RJ, Riddle WR. Analysis of noninvasive macromolecula transport measurements in the lung. J Appl Physiol 1989; 67(6) 2343-50.

[62] Martin-Lefevre L, Ricard JD, Roupie E, Dreyfuss D, Saumon G. Significance of the changes in the respiratory system pressurevolume curve during acute lung injury in rats. Am J Respir Crit Care Med 2001; 164(4): 627-32.

[63] John J, Taskar V, Evander E, Wollmer P, Jonson B. Additive nature of distension and surfactant perturbation on alveolocapillary permeability. Eur Respir J 1997; 10(1): 192-9.

[64] de Prost N, Dreyfuss D, Ricard JD, Saumon G. Terbutaline lessens protein fluxes across the alveolo-capillary barrier during highvolume ventilation. Intensive Care Med 2008; 34(4): 763-70.

[65] Tschumperlin DJ, Oswari J, Margulies AS. Deformation-induced injury of alveolar epithelial cells. Effect of frequency, duration, and amplitude. Am J Respir Crit Care Med 2000; 162(1): 357-62.

[66] de Prost N, Roux D, Dreyfuss D, Ricard JD, Le Guludec D, Saumon G. Alveolar edema dispersion and alveolar protein permeability during high volume ventilation: effect of positive endexpiratory pressure. Intensive Care Med 2007; 33(4): 711-7.

[67] Graf J, Marini JJ. Do airway secretions play an underappreciated role in acute respiratory distress syndrome? Curr Opin Crit Care 2008; 14(1): 44-9.

[68] Kuebler WM. Hitting new barriers in ventilator-induced lung injury. Intensive Care Med 2008; 34(4): 763-70.

[69] Lee JW, Matthay MA. Protein permeability in lung injury: now in real time again? J Appl Physiol 2007; 102(2): 508-9. 